Yudha, M.K. $\cdot$ L. Soesanto $\cdot$ E. Mugiastuti

\title{
Pemanfaatan empat isolat Trichoderma sp. untuk mengendalikan penyakit akar gada pada tanaman caisin
}

\section{The utilization of four Trichoderma sp. isolates for controlling clubroot disease in chinese cabbage}

Diterima : 15 November 2016/Disetujui : 15 Desember 2016 / Dipublikasikan : 30 Desember 2016

CDepartment of Crop Science, Padjadjaran University

\begin{abstract}
The Research aimed to know the effect of application four isolates Trichoderma sp. in controlling disease clubroot and their effect on growth and yield of Chinese cabbage. The research was conducted at the agricultural land experiment the faculty, Jendral Soedirman University, from May 2016 to June 2016. Rendomized block design was used with seven treatments and four replications. The treatments were, control inoculated P. brassicae, control not inoculated P. brassicae, Trichoderma sp. isolates ginger, Trichoderma sp. isolates onions, Trichoderma sp. isolates banana, Trichoderma sp. isolates pineapple, and a fungicide made active Azoksistrobin and Difenokonazol. Variables observed were incubation period, intensity diseases on the land surface, intensity disease under the land surface, plant height, leaves number, fresh weight, and volume clubroot. Result of the research showed that treatment Trichoderma sp. isolates onions could pressing clubroot disease and increase crop yield chinese cabbage, by pressing intensity disease on the land of 50,00 \%, pressing intensity disease under the land 0f $34,48 \%$, lower the volume clubroot of $72,73 \%$, delaying the incubation of $26,65 \%$, increase the number of leaves of $18,12 \%$, and wet weight of $30,75 \%$. Treatment four isolate Trichoderma sp. have not been able to raise hight of Chinese cabbage.
\end{abstract}

Keywords: Chinese cabbage - Plasmodiophora brassicae - Trichoderma sp.

Sari Penelitian ini bertujuan untuk mengetahui pengaruh aplikasi empat isolat Trichoderma sp. dalam mengendalikan penyakit akar gada serta

\begin{tabular}{l}
\hline Dikomunikasikan oleh Ahadiyat Yugi Rahayu \\
\hline Yudha M.K. $\cdot$ L. Soesanto $\cdot$ E. Mugiastuti \\
Program Studi Agroteknologi, Fakultas Pertanian, \\
Universitas Jenderal Soedirman \\
Korespondensi: melindakayudha@gmail.com
\end{tabular}

pengaruhnya terhadap pertumbuhan dan hasil tanaman caisin. Penelitian ini dilaksanakan di lahan percobaan Fakultas Pertanian, Universitas Jenderal Soedirman, mulai Mei 2016 sampai bulan Juni 2016. Penelitian ini menggunakan Rancangan Acak Kelompok (RAK), yang terdiri atas 7 perlakuan dan 4 ulangan. Perlakuan terdiri atas, kontrol diinokulasikan $P$. brassicae, kontrol tidak diinokulasikan $P$. brassicae, Trichoderma sp. isolat jahe, Trichoderma sp. isolat bawang, Trichoderma sp. isolat pisang, Trichoderma sp. isolat nenas, dan fungisida berbahan aktif Azoksistrobin dan Difenokonazol. Variabel yang diamati adalah masa inkubasi, intensitas penyakit di atas permukaan tanah, intensitas penyakit di bawah permukaan tanah, tinggi tanaman, jumlah daun, bobot segar, dan volume akar gada. Hasil penelitian menunjukkan bahwa perlakuan Trichoderma isolat bawang efektif dalam mengendalikan penyakit akar gada dan meningkatkan hasil tanaman caisin, dengan menekan intensitas penyakit di atas tanah sebesar 50,00\%, menekan intensitas di bawah tanah sebesar 34,48\%, menurunkan volume akar gada sebesar $72,73 \%$, menunda masa inkubasi sebesar 26,65\%, meningkatkan jumlah daun sebesar 18,12\%, dan bobot basah sebesar 30,75 $\%$. Perlakuan empat isolat Trichoderma sp. belum mampu meningkatkan tinggi tanaman caisin.

Kata kunci: Caisin - Plasmodiophora brassicae . Trichoderma sp.

\section{Pendahuluan}

Caisin atau caisim (Brassica juncea L.) merupakan komoditas hortikultura yang memiliki nilai komersial dan digemari masyarakat Indonesia. (Haryanto et al., 2001). Menurut data BPS (2015), produksi caisin di Indonesia mengalami 
fluktuasi, pada tahun 2011-2014. Produksi caisin pada tahun 2011 sebesar 580,96 ton naik menjadi 594,93ton pada tahun 2012 dengan persentase kenaikan 2,4\%, naik kembali menjadi 635,72 ton pada tahun 2013 dengan persentase kenaikan $6,85 \%$, dan mengalami penurunan pada tahun 2014 menjadi 602,47 ton dengan persentase penurunan sebesar $5,23 \%$.

Budidaya tanaman caisin memiliki beberapa kendala yang menyebabkan terjadinya penurunan hasil, salah satu di antaranya adanya penyakit akar gada (clubroot) yang disebabkan oleh Plasmodiophora brassicae Wor. Penyakit tersebut salah satu penyakit tular-tanah yang sangat penting pada tanaman kekubisan (Brassica spp.) di seluruh dunia (Karling, 1968). Di Indonesia, penyakit ini menyebabkan kerusakan pada kekubisan sekitar $88,60 \%$ (Widodo dan Suheri, 1995) dan pada tanaman caisin sekitar 5,42-64,81\% (Hanudin dan Marwoto, 2003).

Banyak usaha telah dilakukan untuk mengendalikan patogen tanaman, baik dengan penggunaan tanaman tahan maupun pestisida sintetis. Namun, tanaman tahan terhadap patogen tanaman jarang tersedia, sedangkan pestisida sintetis jika digunakan dengan tidak bijaksana akan banyak menimbulkan masalah, baik terhadap lingkungan, produk tanaman, maupun kesehatan manusia (Soesanto et al., 2013).

Agensia pengendali hayati merupakan salah satu pilihan pengendalian patogen tanaman yang menjanjikan karena murah, mudah didapat, dan aman terhadap lingkungan. Trichoderma sp. merupakan spesies jamur antagonis yang umum dijumpai di dalam tanah, khususnya dalam tanah organik dan sering digunakan di dalam pengendalian hayati, baik terhadap patogen tular-tanah atau rizosfer maupun patogen filosfer. Kisaran inang patogen tanaman yang luas juga menjadi salah satu pertimbangan mengapa jamur ini banyak digunakan (Soesanto, 2013).

Spesies Trichoderma sp. di samping sebagai organisme pengurai, dapat pula berfungsi sebagai agensia hayati. Trichoderma sp. dalam peranannya sebagai agensia hayati bekerja berdasarkan mekanisme antagonis yang dimilikinya (Wahyuno et al., 2009). Purwantisari (2009), mengatakan bahwa Trichoderma sp. merupakan jamur parasit yang dapat menyerang dan mengambil nutrisi dari jamur lain. Kemampuan Trichoderma sp. yaitu mampu memarasit jamur patogen tanaman dan bersifat antagonis, karena memiliki kemampuan untuk mematikan atau menghambat pertumbuhan jamur lain.

Penelitian ini bertujuan untuk mengetahui pengaruh aplikasi empat isolat Trichoderma sp. dalam mengendalikan penyakit akar gada pada tanaman caisin, mengetahui pengaruh aplikasi empat isolat Trichoderma sp. terhadap pertumbuhan tanaman caisin yang terinfeksi penyakit akar gada, dan mengetahui pengaruh aplikasi empat isolat Trichoderma sp. terhadap hasil tanaman caisin yang terinfeksi penyakit akar gada.

\section{Bahan dan Metode}

Penelitian ini dilaksanakan di lahan percobaan Fakultas Pertanian, Universitas Jenderal Soedirman, Kelurahan Karangwangkal, Purwokerto Utara, Kabupaten Banyumas mulai dari bulan Mei 2016 sampai bulan Juni 2016 mulai dari persiapan hingga panen.

Rancangan Percobaan. Penelitian ini menggunakan Rancangan Acak Kelompok (RAK), yang terdiri atas tujuh perlakuan dan empat ulangan. Perlakuan terdiri atas kontrol diinokulasikan $P$. brassicae, kontrol tidak diinokulasikan P. brassicae, Trichoderma sp. isolat jahe, Trichoderma sp. isolat bawang, Trichoderma sp. isolat pisang, Trichoderma sp. isolat nenas, dan fungisida berbahan aktif Azoksistrobin dan Difenokonazol.

Pembuatan Medium PDL dan PDA. Potato Dextrose Liquid (PDL) dibuat dari $200 \mathrm{~g}$ kentang yang di potong kecil dan direbus dalam aquades lalu disaring ekstraknya, kemudian ditambahkan dekstrosa $20 \mathrm{~g}$ untuk membuat larutan PDL dan ditambah $20 \mathrm{~g}$ agar untuk membuat Potato Dextrose Agar (PDA), lalu ditambahkan lagi aquades, sehingga larutan menjadi $1000 \mathrm{~mL}$. Larutan dimasukkan ke dalam erlenmeyer yang telah dipersiapkan, masing-masing sebanyak $100 \mathrm{~mL}$. Medium disterilkan dengan menggunakan autoklaf pada tekanan $1 \mathrm{~atm}$ dan suhu $121^{\circ} \mathrm{C}$ selama 15 menit (Pratomo, 2006).

Persiapan isolat Trichoderma sp. Jamur antagonis Trichoderma sp. isolat jahe, isolat bawang, isolat pisang, dan isolat nenas diperbanyak pada medium PDA (Potato Dextrose Agar), dan diinkubasi hingga miselium memenuhi cawan petri selama lima hari (Latifah et al., 2011). Selanjutnya isolat tersebut dipindah secara aseptis ke dalam PDL (Potato Dextrose Liquid) dalam labu erlenmeyer, dan digojok 
dengan orbital shaker dengan kecepatan 150 rpm selama 4 hari pada suhu kamar (Handaru, 2009). Selanjutnya, dihitung kerapatannya hingga mencapai $10^{6}$ spora per $\mathrm{mL}$.

Penyemaian Benih. Benih direndam dengan air selama 60 menit, kemudian benih disemai pada medium yang telah disiapkan. Proses penyemaian dilakukan dengan sedikit membenamkan benih caisin di permukaan tanah, lalu ditutup dengan halus. Bibit umur 2-3 minggu setelah semai atau yang telah berdaun 3-4 helai, dipindahkan pada polibag sesuai dengan urutan perlakuan (Edi dan Bebihoe, 2010).

Persiapan inokulum $P$. brassicae. Inokulum P. brassicae diperoleh dengan mengumpulkan akar segar caisin atau tanaman jenis Brassicaceae yang bergejala dari daerah pertanaman Brassicaceae. Akar-akar tersebut terlebih dahulu di cuci pada air mengalir untuk menghilangkan sisa-sisa tanah sampai bersih, selanjutnya akar dihancurkan dengan cara diblender kemudian disaring menggunakan kain saring. Kemudian kepadatan spora rehatnya dihitung dengan haemasitometer. Suspensi spora tersebut kemudian dicampurkan ke dalam tanah yang telah disiapkan dengan kepadatan $10^{6}$ spora per $\mathrm{mL}$ bersamaan dengan pindah tanam dari pembibitan (Asniah et al., 2013). Suspensi spora $P$. brassicae yang diinokulasikan ke dalam polibag sebanyak $300 \mathrm{~mL}$ per polibag.

Aplikasi Trichoderma sp. Aplikasi Trichoderma sp. isolat jahe, isolat bawang merah, isolat pisang, dan isolat nenas dilakukan sebanyak lima kali yang diaplikasikan di pembibitan dengan dosis $20 \mathrm{~mL}$ per tanaman, saat tanam dan 5 hst dengan dosis $50 \mathrm{~mL}$ per tanaman, 10 hst dan 15 hst dengan dosis 100mL per tanaman. Pengaplikasian empat isolat Trichoderma sp. dilakukan dengan menuangkan masing-masing isolat ke dalam polibag percobaan sesuai dengan masing-masing perlakuan menggunakan gelas ukur.

Variabel Pengamatan. Pengamatan masa inkubasi dilakukan saat mulai tanam benih tanaman caisin sampai memperlihatkan gejala pertama dengan satuan hari setelah inokulasi (hsi).

Menurut Laksono et al. (2010), intensitas penyakit di atas tanah dihitung sebagai persentase tanaman terserang (disease incidence). Persentase tanaman terserang dihitung dengan cara mehitung jumlah tanaman terserang dikali 100\% dibagi jumlah tanaman sampel.

Pengamatan intensitas penyakit di bawah tanah dilakukan dengan cara mengamati gejala infeksi patogen pada tanaman caisin. Penentuan skala kerusakan akar dilakukan dengan cara mencabut tanaman pada saat dipanen. Menurut Hadiwiyono (1999), keparahan penyakit dihitung dengan metode skor dengan skala kerusakan akar 0 sampai 5. Adapun skor yang digunakan adalah 0 : tidak ada serangan, 1 : kerusakan akar 1-20 \%, 2 : kerusakan akar 21-40 \%, 3 : kerusakan akar 41-60 \%, 4 : kerusakan akar 61-80\%, dan 5 : kerusakan akar lebih dari $80 \%$. Pengukuran keparahan penyakit diukur dengan rumus sebagai berikut:

$$
K P=\frac{\Sigma(\mathrm{nxv})}{N x V} \times 100 \%
$$

Keterangan: KP : keparahan penyakit, $\mathrm{n}$ : jumlah tanaman sakit menunjukkan skor tertentu, $\mathrm{v}$ : skor untuk tanaman sakit, $\mathrm{N}$ : jumlah seluruh tanaman yang diamati, dan $\mathrm{V}$ : skor tertinggi yang digunakan.

Volume akar gada diperoleh dengan cara menghitung volume air setelah akar gada dimasukan dalam gelas ukur dikurangi volume air mula-mula. Penghitungan volume akar dilakukan dengan cara merendam akar pada gelas ukur kemudian diamati peningkatan volume air saat perendaman akar dalam gelas ukur tersebut.

Analisis Data. Data yang diperoleh dianalisis dengan menggunakan uji $\mathrm{F}$ pada taraf kesalahan $5 \%$. Apabila berpengaruh nyata, dilakukan uji lanjut menggunakan DMRT (Duncan's Multiple Range Test) dengan taraf kesalahan $5 \%$.

\section{Hasil dan Pembahasan}

Pengaruh Perlakuan Terhadap Komponen Patosistem. Pengaruh pengaplikasian empat isolat Trichoderma sp. dalam menekan penyakit akar gada pada tanaman caisin dapat diketahui dari komponen patosisitem, yaitu masa inkubasi, intensitas penyakit $\mathrm{di}$ atas permukaan tanah, intensitas penyakit di bawah permukaan tanah, dan volume akar gada (Tabel 1).

Masa inkubasi. Masa inkubasi patogen dihitung sejak inokulasi sampai munculnya patogen. Gejala awal penyakit akar gada dapat dilihat di atas permukaan tanah pada bagian daun yang ditandai dengan terjadinya layu pada siang hari dan segar kembali pada malam serta pagi hari, tanaman merana, dan kerdil. Hal ini sesuai dengan pendapat Semangun (1989), yang mengatakan bahwa tanaman yang terserang patogen akar gada tampak merana, kerdil, daun-daunnya berwarna kelabu dan lebih cepat menjadi layu. 
Tabel 1. Masa Inkubasi, Intensitas Penyakit di Atas Permukaan Tanah, Intensitas Penyakit di Bawah Tanah, dan Volume Akar Gada dari Penyakit Akar Gada Tanaman Caisin.

\begin{tabular}{ccccccc}
\hline \hline Perlakuan & $\begin{array}{c}\text { Masa Inkubasi } \\
\text { (hsi) }\end{array}$ & $\begin{array}{c}\text { Intensitas } \\
\text { Penyakit } \\
\text { di Atas Tanah } \\
(\%)\end{array}$ & $\begin{array}{c}\text { Keefektifan } \\
\text { Pengendalian } \\
(\%)\end{array}$ & $\begin{array}{c}\text { Intensitas } \\
\text { Penyakit } \\
\text { di Dalam Tanah } \\
(\%)\end{array}$ & $\begin{array}{c}\text { Keefektifan } \\
\text { Pengendalian } \\
(\%)\end{array}$ & $\begin{array}{c}\text { Volume } \\
\text { Akar Gada } \\
(\mathrm{mL})\end{array}$ \\
\hline K01 & $19,44 \mathrm{c}$ & $62,50 \mathrm{a}$ & 00,00 & $36,25 \mathrm{ab}$ & 00,00 & $00,69 \mathrm{a}$ \\
K02 & $30,00 \mathrm{a}$ & $00,00 \mathrm{c}$ & - & $00,00 \mathrm{e}$ & - & $00,00 \mathrm{~b}$ \\
K1 & $25,69 \mathrm{ab}$ & $43,75 \mathrm{ab}$ & 30,00 & $30,00 \mathrm{abc}$ & 17,24 & $00,44 \mathrm{ab}$ \\
K2 & $26,50 \mathrm{ab}$ & $31,25 \mathrm{~b}$ & 50,00 & $23,75 \mathrm{bc}$ & 34,48 & $00,19 \mathrm{~b}$ \\
K3 & $22,44 \mathrm{bc}$ & $37,50 \mathrm{ab}$ & 40,00 & $42,50 \mathrm{a}$ & 14,71 & $00,88 \mathrm{a}$ \\
K4 & $26,81 \mathrm{ab}$ & $43,75 \mathrm{ab}$ & 30,00 & $20,00 \mathrm{c}$ & 44,83 & $00,19 \mathrm{~b}$ \\
K5 & $24,13 \mathrm{bc}$ & $25,00 \mathrm{~b}$ & 60,00 & $08,75 \mathrm{~d}$ & 75,86 & $00,00 \mathrm{~b}$ \\
\hline \hline
\end{tabular}

$\overline{\text { Keterangan : Angka yang diikuti huruf yang berbeda pada kolom menunjukkan berbeda nyata antar perlakuan }}$ pada uji DMRT dengan taraf kesalahan $5 \%$. Kontrol diinokulasikan P. brassicae (K01), kontrol tidak diinokulasikan P. brassicae (K02), Trichoderma sp. isolat jahe (K1), Trichoderma sp. isolat bawang (K2), Trichoderma sp. isolat pisang (K3), Trichoderma sp. isolat nenas (K4), Fungisida berbahan aktif Azoksistrobin dan Difenokonazol (K5). (-) tidak dilakukan pengendalian.

Hasil analisis statistika (Tabel 1) menunjukkan adanya pengaruh perlakuan terhadap masa inkubasi. Perlakuan Trichoderma sp. isolat jahe, isolat bawang dan isolat nenas menunjukkan perbedaan nyata dibandingkan dengan tanaman yang tidak diberi perlakuan pengendalian (K01). Hal ini menunjukkan bahwa perlakuan Trichoderma sp. isolat jahe, isolat bawang dan isolat nenas mampu menunda atau memperpanjang masa inkubasi dari patogen $P$. brassicae. Sedangkan Trichoderma sp. isolat pisang tidak berbeda nyata jika dibandingkan kontrol dan perlakuan fungisida. Perlakuan Trichoderma sp. isolat nenas, isolat bawang, dan isolat jahe mampu menunda masa inkubasi masing-masing sebesar yaitu 27,51 \%, 26,65\%, dan $24,33 \%$ dibandingkan dengan kontrol positif dan setara dengan kontrol negatif (kontrol tanpa inokulasi).

Penundaan masa inkubasi tersebut diduga karena adanya jamur Trichoderma sp. Menurut Donzelli et al. (2001) Trichoderma sp. dikenal sebagai jamur yang dapat menghasilkan 1,3- $\beta$ glukanase. Enzim ini dapat mendegradasi dan menghidrolisis dinding sel miselium jamur patogen tanaman selama proses mikoparasit, sehingga berperan dalam mekanisme pertahanan melawan patogen. Hal ini diperkuat oleh Prabowo et al. (2006) penundaan masa inkubasi terjadi karena persaingan antara patogen dengan antagonis, sehingga menyebabkan patogen membutuhkan waktu lebih lama untuk menginfeksi tanaman, karena sistem perakaran didominasi antagonis.

Intensitas Penyakit di Atas Tanah. Hasil analisis statistika (Tabel 1) menunjukkan adanya pengaruh perlakuan terhadap intensitas penya- kit di atas tanah. Perlakuan Trichoderma sp. isolat bawang menunjukkan perbedaan nyata dibandingkan dengan kontrol positif. Hal ini menunjukkan bahwa Trichoderma sp. isolat bawang mampu menekan intensitas penyakit akar gada di atas tanah. Perlakuan Trichoderma sp. isolat bawang mampu menekan intensitas penyakit di atas tanah sebesar $50,00 \%$ dibanding dengan kontrol positif.

Trichoderma sp. isolat pisang, isolat jahe, dan isolat nenas tidak menunjukkan berbeda nyata jika dibanding dengan kontrol positif, tetapi juga tidak berbeda nyata dengan Trichoderma sp. isolat bawang. Hal ini menunjukkan bahwa Trichoderma sp. memiliki kemampuan antagonis yang mampu menghambat perkembangan jamur pada tanaman tersebut, sehingga intensitas penyakit tanaman kecil. Trichoderma sp. mampu menghambat patogen dengan melakukan persaingan, baik dalam hal ruang atau nutrisi dengan jamur patogen (Latifah et al., 2011). Tronsmo (1996), mengatakan bahwa jamur Trichoderma sp. mempunyai mekanisme persaingan dan mampu menghasilkan enzim 1,3- $\beta$-glukanase, kitinase, dan enzim lisis. Kemampuan isolat Trichoderma sp. di dalam menghambat pertumbuhan isolat jamur patogen dipengaruhi oleh kemampuannya bertindak sebagai antagonis, dengan mekanisme yang dimiliki, seperti persaingan dan antibiosis.

Intensitas Penyakit di Dalam Tanah. Intensitas penyakit di dalam tanah dilakukan dengan cara mengamati gejala infeksi patogen pada akar tanaman caisin yang telah dicabut. Gejala yang terlihat pada akar terjadi pembengkakan yang tidak teratur. Hal ini sesuai dengan pendapat Agrios (1997), bahwa pembengkakan 
akar merupakan ciri khas penya-kit akar gada. Bentuk dan letaknya bergantung pada spesies inang dan tingkat infeksi.

Hasil analisis statistika (Tabel 1) menunjukkan adanya pengaruh perlakuan terhadap intensitas penyakit di dalam tanah. Perlakuan Trichoderma sp. isolat nenas menunjukkan perbedaan nyata dibandingkan dengan kontrol. Trichoderma sp. isolat jahe, isolat bawang, dan isolat pisang tidak menunjukkan berbeda nyata jika dibanding dengan kontrol positif, tetapi Trichoderma sp. isolat jahe dan isolat bawang tidak berbeda nyata jika dibandingkan dengan Trichoderma sp. isolat nenas yang menunjukkan adanya potensi untuk menekan intensitas penyakit di dalam tanah. Perlakuan Trichoderma sp. isolat nenas mampu menekan intensitas penyakit di dalam tanah dibanding dengan kontrol positif. Perlakuan Trichoderma sp. isolat nenas mampu menekan intensitas penyakit di dalam tanah sebesar 44,83\% dibanding dengan kontrol positif.

Kemampuan yang tinggi dari Trichoderma sp. isolat nenas di dalam menghambat patogen sesuai dengan pendapat Mukarlina et al. (2010), bahwa jamur Trichoderma sp. diketahui mempunyai kemampuan antagonis yang tinggi dalam menghambat perkembangan jamur patogen tular-tanah. Mekanisme antagonis yang terjadi diduga berkaitan dengan adanya tiga fenomena yang bekerja secara sinergis yaitu kompetisi ruang tumbuh dan nutrisi, mekanisme antibiosis dan interaksi sistem hifa. Pendapat ini diperkuat dengan penelitian Soesanto et al. (2013) Trichoderma sp. isolat nenas nampak yang terbaik daya hambatnya terhadap jamur patogen Fusarium dengan daya hambat sebesar $61,82 \%$.

Volume Akar Gada. Hasil analisis statistika (Tabel 1) menunjukkan bahwa perlakuan Trichoderma sp. isolat bawang dan isolat nenas berpengaruh nyata dibandingkan dengan kontrol. Hal ini menunjukkan bahwa Trichoderma sp. mampu menurunkan volume akar gada pada perakaran tanaman caisin sebesar $72,73 \%$.

Hal ini diduga adanya Trichoderma sp. sudah lebih menguasai perakaran sehingga perakaran tanaman caisin terlindungi dari penyakit akar gada. Hal ini sesuai pendapat Widodo (1993), yang menyatakan bahwa patogen sukar melakukan penetrasi ke tanaman dan menyebabkan penyakit, apabila sistem perakaran terkuasai oleh antagonis. Dwiningsih (1998), juga berpendapat bahwa volume akar gada menunjukkan nilai besarnya hambatan air yang ditranslokasikan ke daun, semakin besar akar gada, maka jumlah hambatan akan semakin besar, dan tanaman akan cepat mengalami kelayuan. Peningkatan penghambatan pertumbuhan tanaman karena pembentuan akar gada, sehingga transpirasi air ke daun terhambat.

\section{Pengaruh Perlakuan Terhadap Komponen Pertumbuhan dan Hasil \\ Tinggi Tanaman. Hasil analisis statistika} (Tabel 2) menunjukkan bahwa perlakuan Trichoderma sp. tidak berpengaruh nyata terhadap peningkatan tinggi tanaman apabila dibandingkan dengan kontrol. Perlakuan Trichoderma sp. tidak berpengaruh terhadap pertumbuhan tanaman diduga karena dipengaruhi oleh faktor dari luar sehingga jamur Trichoderma sp. tidak dapat mengeluarkan zat tertentu yang dapat meningkatkan pertumbuhan tanaman.

Hal ini sesuai dengan pendapat Rao (1992), yang mengatakan bahwa beberapa faktor seperti tipe tanah, kelembapan, $\mathrm{pH}$, suhu, serta umur dan kondisi tanaman mempengaruhi rizosfer. Selain itu Tarman (2006), juga menyatakan bahwa efektifitas Trichoderma sp. ditentukan oleh lamanya masa inkubasi yang tepat pada saat penumbuhan Trichoderma sp. sehingga akan diperoleh jumlah spora yang ideal. Menurut Baihaqi (2013), ruang tumbuh yang kurang cukup untuk pertumbuhan Trichoderma sp. sumber makanan, dan kelembaban udara yang relatif fluktuasi serta mendukung bagi perkembangan jamur patogen, sehingga efesiensi aplikasi Trichoderma sp. juga akan berpengaruh terhadap pertanaman.

Jumlah Daun. Hasil analisis statistika (Tabel 2) menunjukkan bahwa perlakuan Trichoderma sp. isolat bawang dan isolat pisang berpengaruh nyata dibandingkan dengan kontrol dan fungisida. Perlakuan Trichoderma sp. isolat bawang dan isolat pisang mampu meningkatkan jumlah daun tanaman sebesar $18,12 \%$ dibandingkan dengan kontrol positif.

Hal ini menunjukkan bahwa perlakuan Trichoderma sp. sebagai agensia hayati mampu meningkatkan pertumbuhan tanaman, sesuai dengan pernyataan Rahayuniati dan Mugiastuti (2009), bahwa Trichoderma sp. juga mampu menguraikan bahan organik di dalam medium, sehingga menjadi struktur yang lebih sederhana, mudah larut dan dapat dimanfaatkan tanaman sebagai sumber nutrisi untuk pertumbuhan tanaman. Azamri et al. (2011), juga berpendapat bahwa pemberian Trichoderma sp. dapat meningkatkan jumlah dan lebar daun serta mampu meningkatkan kadar klorofil pada daun 
dan benih. Hal ini menunjukkan bahwa Trichoderma sp. memiliki hormon sitokinin.

Tabel 2. Tinggi Tanaman, Jumlah Daun, dan Bobot Segar Tanaman Caisin.

\begin{tabular}{cccc}
\hline $\begin{array}{c}\text { Perla- } \\
\text { kuan }\end{array}$ & $\begin{array}{c}\text { Tinggi } \\
\text { Tanaman } \\
(\mathrm{cm})\end{array}$ & $\begin{array}{c}\text { Jumlah } \\
\text { Daun (helai) }\end{array}$ & $\begin{array}{c}\text { Bobot Segar } \\
(\mathrm{g})\end{array}$ \\
\hline K01 & $43,63 \mathrm{ab}$ & $07,06 \mathrm{~b}$ & $76,13 \mathrm{~b}$ \\
K02 & $41,60 \mathrm{~b}$ & $07,63 \mathrm{ab}$ & $61,06 \mathrm{~b}$ \\
K1 & $41,07 \mathrm{~b}$ & $07,56 \mathrm{ab}$ & $64,88 \mathrm{~b}$ \\
K2 & $46,11 \mathrm{a}$ & $08,63 \mathrm{a}$ & $96,88 \mathrm{a}$ \\
K3 & $46,91 \mathrm{a}$ & $08,63 \mathrm{a}$ & $93,63 \mathrm{a}$ \\
K4 & $40,19 \mathrm{~b}$ & $07,50 \mathrm{ab}$ & $69,94 \mathrm{~b}$ \\
K5 & $34,73 \mathrm{c}$ & 06,75 & $34,06 \mathrm{c}$ \\
\hline \hline
\end{tabular}

Keterangan : Angka yang diikuti huruf yang berbeda pada kolom menunjukkan berbeda nyata antar perlakuan pada uji DMRT dengan taraf kesalahan $5 \%$. Kontrol diinokulasikan P. brassicae (K01), kontrol tidak diinokulasikan P. brassicae (K02), Trichoderma sp. isolat jahe (K1), Trichoderma sp. isolat bawang (K2), Trichoderma sp. isolat pisang (K3), Trichoderma sp. isolat nenas (K4), Fungisida berbahan aktif Azoksistrobin dan Difenokonazol (K5).

Bobot Segar. Hasil analisis statistika (Tabel 2) menunjukkan bahwa Perlakuan Trichoderma sp. isolat bawang dan pisang berpengaruh nyata terhadap bobot segar tanaman. Perlakuan Trichoderma sp. isolat bawang dan isolat pisang dalam meningkatkan bobot segar tanaman masing-masing sebesar 30,75 \% dan 28,35\%.

Peningkatan bobot segar tanaman diduga berkaitan dengan kemampuam Trichoderma sp. dalam menghasilkan hormon pertumbuhan. Hal ini sesuai dengan pendapat Cornejo et al. (2009), bahwa Tichoderma sp. mampu menghasilkan auksin diantaranya adalah IAA. Hormon ini mampu meningkatkan pertumbuhan akar lateral, memperbanyak tunas serta meningkatkan biomasa dari tunas pada tanaman Arabidopsis. Hal ini diperkuat dengan pendapat Haryuni (2013), bahwa Trichoderma sp. Merupakan jamur berfilamen yang bersifat mesofilik, tidak patogen, mempunyai kemam-puan menghidrolisis selulosa dan hemiselulosa menjadi glukosa dan xylosa, dan banyak digunakan untuk memproduksi enzim selulase sehingga meningkatkan biomassa tanaman.

\section{Kesimpulan}

Perlakuan Trichoderma isolat bawang efektif dalam mengendalikan penyakit akar gada dan meningkatkan hasil tanaman caisin, dengan menekan intensitas penyakit di atas tanah sebesar 50,00 \%, menekan intensitas di dalam tanah sebesar 34,48 \%, menurunkan volume akar gada sebesar $72,73 \%$, menunda masa inkubasi sebesar 26,65 \%, meningkatkan jumlah daun sebesar 18,12 \%, dan bobot basah sebesar 30,75 $\%$. Perlakuan empat isolat Trichoderma sp. belum mampu meningkatkan tinggi tanaman caisin.

\section{Daftar Pustaka}

Agrios, G.N. 1997. Plant Pathology. $4^{\text {th }}$ ed. Academic Press, San Diego, California, London. 635hal.

Asniah, Widodo, dan S. Wiyono. 2013. Potensi cendawan asal tanah perakaran bambu sebagai endofit dan agen biokontrol penyakit akar gada pada tanaman brokoli. J. HPT Tropika.13(1): 61-68.

Azamri, R., B. Hajieghrari, and A. Giglou. 2011. Effect of Trichoderma isolates on tomato seedling growth response and nutrient uptake. African Journal of Biotechnology. 10(31): 5850-5855.

Baihaqi, A., M. Nawawi, dan A.L. Abadi. 2013. Teknik aplikasi Trichoderma sp. terhadap pertumbuhan dan hasil tanaman kentang (Solanum tuberosum L). Jurnal Produksi Tanaman. 1(3): 30-39.

Cornejo, H.A.C., L.M. Rodriguez, C.C. Penagos, and J.L. Bucio. 2009. Trichoderma virens a plant benefical fungus, enhances biomass production and promotes lateral root growth through an auxin-dependent mechanism in arabidopsiss. Plant Fisiology. 14(9): 1579-1592.

Donzelli, B.G., M. Lorito, F. Scala, and G. E. Harman. 2001. Cloning, sequence and structure of a gene encoding an antifungal glucan 1,3-âglucosidase from Trichoderma atroviride (T. herzianum). Gene. 27(7): 199-208.

Dwiningsih. 1998. Evektivitas kombinasi antagonis, mulsa daun tanaman dan pengapuran terhadap penekanan penyakit akar gada pada caisin. Skripsi. Fakultas Pertanian, Universitas Jenderal Soedirman, Purwokerto. (Tidak Dipublikasikan).

Edi, S., dan J. Bobihoe. 2010. Budidaya Tanaman Sayuran. Balai Pengkajian Teknologi Pertanian (BPTP) Jambi. Jambi. 54hal.

Hadiwiyono. 1999. Jamur akar gada (Plasmodiophora brassicae Wor.): uji toleransi inang dan pengendaliannya secara hayati dengan Trichoderma. Pp. 365-371 Dalam: Soedarmono, 
T., T. Arwiyanto, S. Donowidjojo, H.A. Djatmiko, D.S. Utami, N. Prihatiningsih, E. Pramono, A. Manan, dan E. Mugiastuti, Penyunting. Prosiding Kongres Nasional XV dan Seminar Ilmiah Perhimpunan Fitopatologi Indonesia, Purwokerto, 16-18 September 1999.

Handaru, O.D. 2009. Pengimbasan ketahanan bibit pisang ambon kuning terhadap penyakit layu fusarium dengan beberapa jamur antagonis. Skripsi. Fak. Pertanian Unsoed, Purwokerto. Tidak dipublikasikan.

Hanudin, dan B. Marwoto. 2003. Pengendalian penyakit layu bakteri dan akar gada pada tanaman tomat dan caisin menggunakan Pseudomonas fluorescens. Jurnal Hortikultura. 13(1): 58-66.

Haryanto, E., T. Suhartini, dan E. Rahayu. 2001. Sawi dan Selada. Penebar Swadaya. Jakarta.

Haryuni. 2013. Perbaikan pertumbuhan dan hasil Stevia (Stevia rebaudiana BERTONI M) melalui aplikasi Trichoderma sp. Biosaintifika. 5(2):58-63.

Karling, J.S. 1968. The Plasmodiophorales. 2nd ed. Hafner Publ. Co., New York and London. 256 p.p.

Laksono, K.D., C. Nasahi, dan N. Susniahti. 2010. Infentarisasi penyakit pada tanaman jarak pagar (Jatropha curcas L.) pada tiga daerah di Jawa Tengah. Jurnal Agrikultura. 21(1): 31-38.

Latifah, A, Kustantinah, dan L. Soesanto. 2011. Pemanfaatan beberapa isolat Trichoderma harzianum sebagai agensia pengendali hayati penyakit layu Fusarium pada bawang merah in Planta. Eugenia. 17(5):86-94.

Mukarlina, S. Khotimah, dan R. Rianti. 2010. Uji antagonis Trichoderma herzianum terhadap Fusarium sp. penyebab penyakit layu pada tanaman cabai (Capsicum annum) secara in vitro. J. Fitomedika. 7(2): 80-85.

Prabowo, A.K.E., N. Prihatiningsih, dan L. Soesanto. 2006. Potensi Trichoderma harzianum dalam mengendalikan Sembilan isolat Fusarium oxysporum Schlecht.f.sp. zingiberi Trujillo pada kencur. Jurnal Ilmu-Ilmu Pertanian Indonesia. 8(2):76-84.

Pratomo, R. 2006. Pengaruh Macam, pH, dan Penggoyangan Media Terhadap Pertumbuhan Cendawan Rizoctonia sp. Sripsi. Fak. Kehutanan Institut Pertanian Bogor. Bogor.
Purwantisari, S. 2009. Isolasi dan identifikasi cendawan indigenous rhizosfer tanaman kentang dari lahan pertanian kentang organik di Desa Pakis. Magelang. Jurnal BIOMA. 11(2):45.

Rahayuniati, R.F., dan E. Mugiastuti. 2009. Pengendalian penyakit layu fusarium tomat: aplikasi abu bahan organik dan jamur antagonis. Jurnal Pembangunan Pedesaan. 9(1) : 25-34.

Rao, N.S.S. 1992. Mikroorganisme Tanah dan Pertumbuhan Tanaman. Diterjemahkan oleh H. Susilo. 1994. UI Press, Jakarta. 353hal.

Semangun, H. 1989. Penyakit-Penyakit Tanaman Hortikultura Di Indonesia. Gadjah Mada Univ. Press, Yogyakarta. 850hal.

Soesanto L. 2013. Pengantar Pengendalian Hayati Penyakit Tanaman. Edisi 2. Rajawali Pers. Jakarta. 456hal.

Soesanto, L., E. Mugiastuti, R.F. Rahayuniati, dan R.S. Dewi,. 2013. Uji kesesuaian empat isolat Trichoderma spp. dan daya hambat in vitro terhadap beberapa patogen tanaman. J. HPT. Tropika. 13(2):117-123.

Tarman, P.E. 2006. Pengaruh lama masa inkubasi jamur antagonis Trichoderma herzianum terhadap daya hambat perkembangan jamur patogen Fusarium oxysporum penyebab penyakit layu tanaman tomat secara in vitro. (On-line). Diakses 12 Oktober 2016

Tronsmo, A. 1996. Trichoderma harzianum in Biological Control of Fungal Disease. Pp.212-221. In: R. Hall (ed.), Principles and Practise of Managing Soil Borne Plant Pathogens. APS Press, St. Paul, Minenesota.

Wahyuno, D., D. Manohara, dan K. Mulya. 2009. Peranan bahan organik pada pertumbuhan dan daya antagonisme Trichoderma harzianum dan pengaruhnya terhadap $P$. capsici. pada tanaman lada. Jurnal Fitopatologi Indonesia. 7:76-82.

Widodo. 1993. Penggunaan Pseudomonas kelompok Fluorescens untuk mengendalikan penyakit akar gada pada caisin (Brassica campestris var. chinensis). Tesis Pasca Sarjana. IPB, Bogor. 41hal (Tidak dipublikasikan).

Widodo and Suheri. 1995. Suppression of clubroot disease of cabbage by soil solarization. Buletin Hama Penyakit Tumbuhan. 8(2):49-55. 